\title{
The Challenges of Developing Online Learning
}

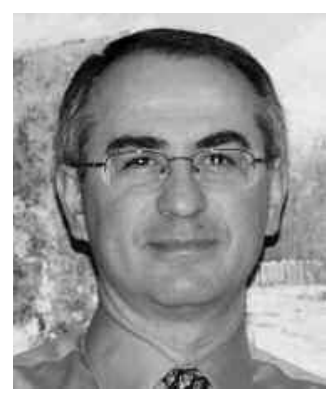

Musculoskeletal (MSK) conditions are common in healthcare practices and have been identified as the leading cause of chronic health problems, longterm disability, and consultations with health professionals in Canada ${ }^{1-3}$. In 1998, it was estimated that MSK issues accounted for about $20 \%$ of the daily care administered by family practitioners ${ }^{4}$. It is also known that signs and symptoms of MSK conditions may be underdiagnosed by primary care physicians, and the examination of this system is often omitted from routine patient assessments ${ }^{5,6}$. Some primary care physicians may not feel they can alter the clinical course by early detection, for example in the case of osteoarthritis. Studies of medical students and practicing physicians have cited a lack of interest and/or a lack of perceived importance of the MSK system, time constraints, and an overall lack of confidence in providing assessment as reasons for discomfort with managing patient MSK conditions ${ }^{5,7-11}$.

The average number of hours devoted to teaching MSK clinical skills at Canadian medical schools is limited compared to the prevalence of MSK complaints in the population. Canadian schools' preclerkship MSK clinical skills teaching is heavily dependent on the contributions of nonMSK specialists ${ }^{12}$. Pinney and Regan concluded that there is a marked discrepancy between the MSK knowledge and skill requirements of a primary care physician and time devoted to MSK education in Canadian medical schools ${ }^{13}$.

The report by Averns, et al in this issue of The Journal demonstrates the usefulness and effectiveness of using an online module for teaching the examination of the hand by medical students. Three groups of students were exposed to a Web-based module, tutorial-based learning, or independent study of a standard textbook, respectively ${ }^{14}$. Test results revealed that the students using the module had significantly higher scores than the students using either of the other study methods. These results are encouraging in that many online evaluations generally report equivalent results between face-to-face learning and Web-based learning.

It is important to identify who the learners are and how they learn. The educational literature generally considers 4 age groups: Matures (born prior to 1946), Baby Boomers (1946-1964), Generation X (1965-1980), and Millennials (1981-1994) or Net-Generation ${ }^{15}$.

Our current crop of learners, the Millennials, is a more diverse group than ever before. They are more technologically advanced than their faculty, with $84 \%$ reporting owning a computer before entering post-secondary institutions, and $90 \%$ accessing the Internet daily ${ }^{16}$. Millennials exhibit different learning styles. They are more comfortable with experiential activities, and tend toward teamwork, structure, and the use of technology ${ }^{17}$.

Many faculty and universities are experimenting with courses using both face-to-face and online instruction. This blended learning approach has its roots in the corporate world and is rapidly gaining ground at academic institutions.

At McMaster University, in Hamilton, Canada, the entire medical undergraduate curriculum is available online. This is supplemented by large-group lectures, which are available online for asynchronous learning and review. Teaching and learning clinical skills presents challenges for faculty and students as the program has grown from 100 to 180 students over only a few years, with no increase in human resources. Innovative approaches are required to deliver content with limited faculty resources. Teaching clinical skills is labor-intensive, delivered in a small-group format, and can be of variable quality and consistency ${ }^{18}$.

In their metaanalysis, Cook, et al ${ }^{19}$ summarized the effect of Internet-based instruction for health professional learners compared with no intervention and with nonInternet interventions. The study revealed that Internetbased learning is associated with large positive effects compared with no intervention; however, overall, compared with non-Internet instructional methods, the effect was small, suggesting effectiveness similar to traditional methods ${ }^{19}$.

In a case study of student satisfaction, blended learning

See Evaluation of Web-based teaching module on examination of the hand, page 623 
was shown by $\mathrm{So}^{20}$ to be an effective method. Key elements of a successful program were integration of technology components and instructional design strategies. So explains further: "To be more learner-centered, the learning environment needs to be designed to allow individual learning, as well as to create opportunities for interaction with other classmates and the instructors. For effective online communication, it is important to provide channels for both synchronous (e.g., face-to-face meetings) and asynchronous (e.g., online discussion forums) interactions. Finally, the online learning environment should include a place where students can receive socioemotional support to reduce their feeling of frustration, isolation, and dissatisfaction, as well as to provide content-related support for cognitive learning." 20

No educational resource will achieve its full potential when used exclusively. Sharing online assets in a repository such as the Health Education Assets Library (HEAL) is the way to go. With a mission to provide free digital resources of the highest quality that meet the needs of today's health sciences educators and learners, HEAL promotes the preservation and exchange of useful educational assets while respecting ownership and privacy ${ }^{21}$.

\section{ALFRED CIVIDINO, MD Clinical Professor, Head, Service of Rheumatology, Hamilton Health Sciences, McMaster University, Hamilton, Ontario, Canada}

\section{REFERENCES}

1. Leistner K, Wessel G, Allander E. Medium-term trends in the occurrence of rheumatic diseases in European countries. Results of an inquiry on statistical data. Scand J Rheumatol 1986;15:206-18.

2. Walker JG, Littlejohn GO. Measuring quality of life in rheumatic conditions. Clin Rheumatol 2007;26:671-3.

3. Badley EM, Webster GK, Rasooly I. The impact of musculoskeletal disorders in the population: are they just aches and pains? Findings from the 1990 Ontario Health Survey. J Rheumatol 1995;22:733-9.

4. Martel L, Caron Malenfant E. Portrait of the Canadian population in 2006, by age and sex: findings. Statistics Canada; 2007. [Internet. Accessed January 6, 2009.] Available from: http://www12.statcan.ca/english/census06/analysis/agesex/index.cfm

5. Lillicrap MS, Byrne E, Speed CA. Musculoskeletal assessment of general medical in-patients — joints still crying out for attention. Rheumatology Oxford 2003;42:951-4.
6. Plant MJ, Linton S, Dodd E, Jones PW, Dawes PT. The GALS locomotor screen and disability. Ann Rheum Dis 1993;52:886-90.

7. Glazier RH, Dalby DM, Badley EM, Hawker GA, Bell MJ, Buchbinder R. Determinants of physician confidence in the primary care management of musculoskeletal disorders. J Rheumatol 1996;23:351-6.

8. Walker DJ, Kay LJ. Musculoskeletal examination for medical students: the need to agree what we teach. Rheumatology Oxford 2002;41:1221-3.

9. Jones A, Doherty M. The time has come, the walrus said.... Ann Rheum Dis 1992;51:434-5.

10. Doherty M, Abawi J, Pattrick M. Audit of medical inpatient examination: a cry from the joint. J R Coll Physicians Lond 1990;24:115-8.

11. Dequeker J, Rasker H. High prevalence and impact of rheumatic diseases is not reflected in the medical curriculum: the ILAR Undergraduate Medical Education in Rheumatology (UMER) 2000 project. Together everybody achieves more. International League of Associations for Rheumatology. J Rheumatol 1998;25:1037-40.

12. Oswald AE, Bell MJ, Snell L, Wiseman J. The current state of musculoskeletal clinical skills teaching for preclerkship medical students. J Rheumatol 2008;35:2419-26.

13. Pinney SJ, Regan WD. Educating medical students about musculoskeletal problems: Are community needs reflected in the curricula of Canadian medical schools? J Bone Joint Surg Am 2001;83:1317-20

14. Averns H, Maraschiello M, van Melle E, Day A. Evaluation of a Web-based teaching module on examination of the hand. J Rheumatol 2009;36:623-7.

15. Dziuban C, Hartman J, Moskal PD. Blended learning. [Internet. Accessed January 6, 2009.] Available from: http://connect. educause.edu/Library/ECAR/BlendedLearning/40089

16. The pocket guide to higher U.S. education 2005. [Internet. Accessed January 6, 2009.] Available from: http://net.educause.edu/ir/library/pdf/PUB2201.pdf

17. Oblinger D. Boomers, Gen-Xers, and Millennials: understanding the new students. EDUCASE Review, Volume 38, Number 4, 2003 37-47. [Internet. Accessed January 6, 2009.] Available from: http://net.educause.edu/ir/library/pdf/erm0342.pdf

18. Kay L, Walker D. Improving musculoskeletal clinical skills teaching. A regionwide audit and intervention study. Ann Rheum Dis 1998;57:656-9.

19. Cook DA, Levinson AJ, Garside S, Dupras DM, Erwin PJ, Montori VM. Internet-based learning in the health professions: a metaanalysis. JAMA 2008;300:1181-96.

20. So HJ. Is blended learning a viable option in public health education? A case study of student satisfaction with a blended graduate course. J Public Health Manag Pract 2009;15:59-66.

21. The Health Education Assets Library. [Internet Home Page. Accessed January 6, 2009.] Available from: http://www.healcentral. org/index.jsp

J Rheumatol 2009;36:470-1; doi:10.3899/jrheum.090007 